\title{
Setting the Agenda for Reproductive and Maternal Health in the Era of COVID-19: Lessons from a Cruel and Radical Teacher
}

\author{
Lois McCloskey ${ }^{1}$ (1) $\cdot$ Ndidiamaka Amutah-Onukagha ${ }^{2} \cdot$ Judith Bernstein ${ }^{3} \cdot$ Arden Handler $^{4}$
}

Accepted: 5 November 2020 / Published online: 7 January 2021

○) Springer Science+Business Media, LLC, part of Springer Nature 2021

\begin{abstract}
Background COVID-19 exposes major gaps in the MCH safety net and illuminates the disproportionate consequences borne by people living in low resource communities where systemic racism, community disinvestment, and social marginalization creates a perfect storm of vulnerability.

Methods We draw eight lessons from the first 8 months of the pandemic, describing how COVID-19 has intensified preexisting gaps in the MCH support network and created new problems. For each lesson identified, we present supporting evidence and a call for specific actions that can be taken by $\mathrm{MCH}$ practitioners, researchers and advocates.

Results LESSON \#1: COVID-19 hits communities of color hardest, exposing and exacerbating health inequities caused by systemic racism. LESSON \#2: Women experience the most devastating social, economic and mental health tolls during COVID-19. LESSON \#3: Virulent pathogens find and exacerbate cracks in our public health and health care systems. LESSON \#4: COVID-19 has become a pretext to limit access to sexual and reproductive health care. LESSON \#5: COVID-19 has exposed and deepened fault lines in maternity care: over-medicalization, discrimination, lack of workforce diversity, underutilization of collaborative team approaches, and lack of post-delivery follow-up. LESSON \#6: The pandemic adds impetus to much-needed Medicaid policy reforms that can have a lasting positive effect on maternal health. LESSON \#7: Social and health policy changes, heretofore deemed infeasible, ARE possible under pandemic threat. LESSON \#8: Finally, an overarching COVID-19 lesson: We are all inextricably connected.
\end{abstract}

Conclusion COVID-19 is a loud wake up call for renewed action by MCH epidemiologists, policy-makers, and advocates.

Keywords COVID-19 $\cdot$ Maternal health $\cdot$ Reproductive health

Lois McCloskey

loism@bu.edu

Ndidiamaka Amutah-Onukagha

ndidiamaka.amutah_onukagha@tufts.edu

Judith Bernstein

jbernste@bu.edu

Arden Handler

handler@uic.edu

1 Department of Community Health Sciences, Center of Excellence in Maternal and Child Health Education, Science and Practice, Boston University School of Public Health, 801 Massachusetts Avenue I CT 436 I, Boston, MA 02118, USA
2 Department of Public Health and Community Medicine, Tufts University School of Medicine, Boston, USA

3 Department of Community Health Sciences, Boston University School of Public Health, 801 Massachusetts Avenue, Boston, MA 02118, USA

4 Division of Community Health Sciences and Center of Excellence in Maternal and Child Health, University of Illinois School of Public Health, 1603 W. Taylor, Chicago, IL 60612, USA 


\section{Significance Statement}

COVID-19 exposes and exacerbates deep racial inequities and economic injustice in society and harmful gaps in public health and health care systems in the U.S. The pandemic also opens doors for social and policy reforms once thought impossible. This article explores key lessons of the historic moment, implications for maternal health, and proposes an agenda for $\mathrm{MCH}$ practitioners, advocates, and scholars. It is a good time to take stock and double down on existing commitments for health equity, adopt broad and bold approaches, and elevate the health and well-being of pregnant and parenting people whose work and lives are essential to all communities.

\section{Introduction}

COVID-19 has been a cruel and radical teacher, laying bare the underlying inequities that shape its disproportionate impact on communities of color, with enormous implications for what we as $\mathrm{MCH}$ practitioners and scholars hold dear: the opportunity to promote the strength and well-being of all pregnant and parenting people, ${ }^{1}$ children, and families in less resourced communities that bear the brunt of systemic racism, community disinvestment, and social marginalization and now COVID-19. We draw eight lessons from the first eight months of the pandemic to highlight new opportunities for action and renewed and sustained commitment. This commentary opens a conversation about how we can apply these lessons to re-imagine a broader, bolder $\mathrm{MCH}$ going forward. We use a reproductive justice lens, defined as "the human right to maintain personal bodily autonomy, have children, not have children, and parent the children we have in safe and sustainable communities" (Ross and Solinger 2017) to assess the impact of the pandemic on women and their families.

LESSON \#1: Recognition that COVID-19 hits communities of color hardest, exposing and exacerbating longstanding health inequities caused by the systemic racism that runs deep in U.S. history, is an important first step. COVID-19 is a loud wake up call for renewed action by $\mathrm{MCH}$ epidemiologists, policy-makers, and advocates.

\footnotetext{
1 Throughout this commentary, we use the terms "pregnant people", "women", and "mothers" interchangeably to convey the distinct yet overlapping people affected by what we traditionally call "Maternal Health".
}

\section{The Evidence}

In early April, 2020 investigative reporters first unplugged the silence about the disparate impact of COVID-19 on communities of color (Johnson and Buford 2020; Hedgpeth et al. 2020; Garg et al. 2020). Since then, data on COVID-19 continues to expose how pre-existing racial and social injustice leaves marginalized communities vulnerable.

Under conditions of scarcity, stress, and uncertainty, the delivery of medical care is more likely to be affected by racial bias (Bloche et al. 2003), which then furthers existing health inequities. Structural racism shapes who gets what, when, and how, from disrespect of Black mothers during pregnancy and childbirth to the lack of clean water in Flint MI and Native American reservations. During COVID-19, this means that the color of one's skin-not the severity of symptoms-determines access to timely testing, hospitalization, treatment, PPE and community resources, and even how information is disseminated (Farmer 2020). In at least one state (MA), guidelines initially developed by hospital administrators for rationing ventilators disproportionately disadvantaged people with prior conditions rooted in structural racism, pointing out the need for an equity lens. Community and clinician pressure prompted revisions, allowing for more equitable access to appropriate care for serious COVID-19 symptoms (Crisis Standards of Care Advisory Committee 2020).

\section{Call for Action}

Advocate for universal mandates for timely reporting of race- and class-related data during wave 2 of this pandemic and for future disasters, and build in accountability measures to ensure that equitable allocation of resources is driven by specific and stratified data.

$\mathrm{MCH}$ professionals must continue to push for data that illuminates the intersectionality of race and class, race/ethnicity, and sex through simultaneous stratification. We need to track and expose how BIPOC, LGBTQiA communities, unhoused and food insecure people, those with disabilities, workers on the frontlines of essential services, and those with substance use histories and mental health conditions are faring. We need standardized indicators that capture if and how racism and discrimination of all types play out in access to COVID-19 testing and infection and death rates. We know from patient narratives, for example, that access to substance abuse treatment has been severely restricted during the pandemic, despite telemedicine and efforts to create detox beds for women with SUD who test positive (Volkow 2020), but Massachusetts and other states have suspended release of SUD data since March, 2020. We need narratives to illuminate individual stories about how women 
experience COVID-19, their contacts with health care, and the relevance to them of public health messages. Then we need to share the data and stories widely to prompt national, state and institution-based policy protections.

LESSON \#2: Women have experienced the most devastating social, economic and mental health tolls during COVID-19, even though men appear to be more susceptible to infection and death.

\section{The Evidence}

Data suggest that worldwide men are more likely to be infected and to die of COVID-19 than women (Courage 2020), but the status of mothers at home and in the workforce places them in the eye of the storm as the pandemic rolls out in waves. The disparate impact on women has led many to call the economic crisis of 2020, the "shecession" (Holpuch 2020).

Regardless of income and marital status, women do a disproportionate share of childcare and household unpaid labor, and the burden is highest for those who earn low wages and are single with young children (Lewis 2020). In fact, by October 1, 2020, more than four times as many women than men $(865,000$ vs. 219,000$)$ had dropped out of the labor force, reflecting women's outsized caregiving role and in many cases, lower wages (Gupta 2020).

Mothers are breadwinners or co-breadwinners in twothirds of American families; likewise, two-thirds of low wage workers are women, half of them single mothers (Tucker and Patrick 2017). More than $80 \%$ of Black mothers are key breadwinners for their families (Glynn 2019), and the gender pay gap is particularly stark for Black and Native American women ( $\$ 0.75$ cents to the dollar of White men vs. $\$ 0.81$ for White women) (The State of the Gender Pay Gap 2020). Not surprisingly, in the first wave of pandemic layoffs in March 2020, 60\% of the jobs that were eliminated were held by women (Horsley 2020). Against this backdrop of built-in income inequality, Latina and Black women also have suffered the highest rates of unemployment during the pandemic, reaching 11\% in September, compared to 6.5\% for White men and 6.9\% for White women (Kochhar June $9,2020)$. The disparity is due in part to the high numbers of Latina and Black women who worked in the leisure and hospitality industries, a sector that suffered huge job losses in the early months of COVID-19.

While women have lost jobs in untold numbers, the opposite is also true. According to the NY Times (April $18,2020)$, more than one in three jobs held by women are deemed essential, putting women and typically low-income women of color at increased risk of contracting COVID-19. In particular, 2.3 million home care workers, mostly women of color and immigrants, are not adequately protected under decades-old labor laws (Burnham and Theodore 2012). Women make up a striking $85 \%$ of home health, personal care workers, and housekeeping workers-low-paying evening and weekend work without benefits, and are insecure and poorly paid in the best of times. It is a tragic and telling irony that these workers continue to care for the most vulnerable elders and chronically ill patients during COVID-19, rendering them at once "essential" and "expendable" (Crenshaw et al. 2020), with a disproportionate number of COVID-19 deaths among young women who are nursing home aides, transit workers, and grocery store clerks (Schnall 2020).

Evidence generally points to upticks in the prevalence and severity of intimate partner violence (IPV) in disaster settings (First et al. 2017). As expected, the incidence and severity of IPV increased during the COVID pandemic as compared to three previous years of data (Gosangi et al. 2020). Public health messaging declares that "the safest place you can be right now is at home," but we know that home is not safe for many. The precursors to intimate partner violence, such as financial stress and alcohol use, are heightened under the strain of the pandemic and the consequences endure past the immediate crisis (Velonis and McGown 2020; Evans et al. 2020).

\section{Call for Action}

Call for and collect gender-specific data, stratified by race/ ethnicity, and systematically compile stories about the web of economic and health impacts on women, with focus on women of color and essential workers. Reinvigorate the research and policy agenda for women's work, domestic violence, Black maternal health, and mental health.

In a field defined by a commitment to the holistic needs of families doubly hit by poverty and racism, maternal health scholars and advocates must do better at aligning our work with colleagues who are front and center in the fight for economic justice, labor rights, and social policies that prioritize living wages, paid sick time and family leave, and other benefits needed by women workers.

In domestic violence, $\mathrm{MCH}$ professionals have a particular role to play documenting and addressing the sustained impacts on survivors of IPV, once the immediate COVID-19 virus crisis has passed.

In this nation, we cannot afford to backslide from our heightened commitment to Black maternal health, only recently granted the attention it deserves in mainstream media, research, and program funding. The intersectionality of Black women's vulnerabilities must be at the forefront of the maternal health agenda. This can only happen with leadership from Black and indigenous people of color (BIPOC), and people with lived experience of inequities, engaged at all stages of planning and implementing a reinvigorated research and policy agenda. 
The burdens mothers are shouldering during the pandemic call for expanded resources devoted to maternal mental health, including and beyond the postpartum period. During the pandemic and in its aftermath, program and research funding should include specific investments in mothers of school-aged children.

LESSON \#3: COVID-19 and other virulent pathogens find the cracks in our public health and health care systems, and wreak havoc on access to services and workforce capacity.

\section{The Evidence}

A great deal of ink has been spilled on the failures of the U.S. to prepare adequately for a pandemic by stockpiling goods and planning fair distribution. Much less discussion has been devoted to the longstanding cracks in our public health infrastructure and health care system that limit the ability of both health care and public health systems to address the pandemic (Interlandi 2020). The significance of chronic underfunding of the public health infrastructure in the U.S. (three cents to each dollar of health care spending) is now starkly visible. The DeBeaumont Foundation, which tracks public health workforce trends, rang a prescient alarm bell in 2019: "We are allowing the skills in the governmental public health agency workforce to slowly erode. It may not be immediately noticeable, but there will come a crisis for which we are completely unprepared." (Castrucci and Fraser 2019). Here we are.

Between 2008 and 2017, local health departments lost 50,000 jobs that have never been refilled, including epidemiologists, lab scientists, public health information specialists, and nurses who are the backbone of Women Infants and Children Program (WIC), Maternal, Infant, Early Childhood Home Visiting (MIECHV), Healthy Start Initiative (HSI) and other MCH programs (Fauteux 2008), prompting warnings of a shortfall of more than 250,000 public health workers by 2020 (Association of Schools and Programs of Public Health 2008). Large urban health departments cut their public health nurse workforce over the last two decades (US Department of Health and Human Services 2013), as the historic $\mathrm{MCH}$ focus shifted to population health and systems building. Many remaining MCH-oriented PHN's have had to abandon their usual roles to bolster the COVID-19 response, leaving pregnant people and families with little support.

Similarly, the nation's 1432 community health centers (CHC's) play an enormous role in $\mathrm{MCH}$ due to the large proportion of their 26 million patients who are mothers and children with Medicaid and/or CHIP insurance (Rosenbaum 2017). CHC's also serve as a first line of defense for people with COVID-19. Sadly, these hubs of primary and urgent care have had to fight for their own financial security despite the crisis. In the stimulus package signed into law on March
27, 2020, the Community Health Fund that accounts for $70 \%$ of $\mathrm{CHC}$ federal grant funding was re-authorized only through November 2020.

COVID-19 is presenting unprecedented demands on state health departments (Bokios 2020). The MCH Block Grant/ Title $\mathrm{V}$ has been underfunded for years $(\$ 703.9$ million in FY 2000, but only $\$ 677.7$ million in FY 2019. Title V staff in state agencies have high turnover. low pay and lack of opportunity for advancement (Association of Maternal and Child Health Programs 2017), and many have been deployed to COVID response, forcing many Title $\mathrm{V}$ programs to place the many issues confronting women and children on the "back-burner".

\section{Call for Action}

Increase federal funding of the state Title V block grant. The current pandemic makes painfully clear the importance of a higher investment in the state Title V block grant in non-disaster times to increase workforce wages and benefits, develop crisis preparedness and response, and implement a more holistic and cross-sectoral agenda for maternal health.

Assure flexible and robust $\mathrm{MCH}$-oriented surveillance to describe impacts and respond when new hazards arise. Systems that can immediately begin to track the experiences of pregnant women (e.g., birth defects registries, PRAMS) must be on the ready despite lagging resources, and going forward, systems should include questions about exposure and access to testing and treatment.

Strengthen the clinical care infrastructure, continue reimbursement for telehealth options particularly in areas where transportation is limited, and assist safety net hospitals at the center of the pandemic to recover and rebuild capacity to provide increased quality access to health care for communities of color. Particularly, they can monitor federal reimbursements to these hospitals under COVID-19 legislation and strengthen community input about hospital and hospital service closure and resource allocation. $\mathrm{MCH}$ professionals are well poised to provide data to shift the metric for funding to address inequities that result in communities of color getting sicker at younger ages (pre-Medicare eligibility).

LESSON \#4: COVID-19 lays bare and exacerbates cracks in the health care system for sexual and reproductive health. COVID-19 lays bare and exacerbates cracks in the health care system for sexual and reproductive health.

\section{The Evidence}

During crises, menstruation, sex, pregnancy, and the need for contraception and abortion care do not go on pause. The pandemic has raised additional barriers to transportation (system shutdowns), childcare (center closures and home 
schooling), and housing (inability to pay rent). Social distancing also magnifies the challenges for pregnant and parenting people.

The Trump Administration's 'gag rule' has cut in half the network of Title X clinics, with 900 clinics closing and as many as 1.6 million patients, most of them women of color and uninsured women, with no reliable source of primary care and contraception (Dawson 2020). During the first week in March 2020, just as COVID-19 social distancing guidelines were rolling out, the requirement that Title $\mathrm{X}$ services and abortion services be physically separate went into effect, with further family planning losses expected. Despite the Supreme Court's repeated rulings that abortion is a constitutionally protected right that cannot be hindered by 'undue burden', more than 150 restrictive laws have been passed in the last three years alone (Nash et al. 2019). Potential changes on the Supreme Court after the death of Ruth Bader Ginsburg put Roe v. Wade protection in real jeopardy. Highly restrictive laws do harm, often by delaying abortions beyond the first trimester (Solazzo 2019). Harms are greatest among those living in poverty, people of color, rural women, LGBTQiA+ people, immigrants, and all people living in states that place low priority on reproductive health and justice.

COVID-19 provided conservative governors with an opening to achieve goals to erode access to abortion. As states called for nonessential medical procedures to be halted in March 2020, eleven governors excluded abortion care from the essential services, acting in direct opposition to public health and medical expert advice. The American College of Obstetrics and Gynecology (ACOG) deems abortion to be an 'essential' and time-sensitive health procedure and argued that banning the procedure leads to illegal unsafe abortions and would further strain resources needed to fight the pandemic (Sobel et al. 2020). Courts eventually prohibited the executive actions, but in at least four states abortion services were temporarily interrupted, forcing women to delay or forgo needed abortions or travel long distances out of state to access it - all with deleterious consequences for women's health and well-being (Sobel et al. 2020; Atkins 2020; Enda 2020).

COVID-19 highlights the vulnerability of our abortion care system and the prevailing notion that most abortions are "elective", now misconstrued as "not essential" (Bayefsky et al. 2020).

Medication abortion is also highly restricted in the U.S. with wide variations by state, rendering the two emerging non-clinic based modes of delivery, telehealth proscribing and direct mail order, extremely challenging to implement (Wells and Coeytaux 2016). Currently 32 states require the administering clinician to be a physician, and in 18 states the clinician must be 'physically present' (Guttmacher Institute 2020; Baker 2020). In June 2019 the first published evidence of feasibility and acceptability of a direct-to-patient model of telemedicine for abortion in the U.S. was published (Raymond et al. 2019), with promising results similar to those reported in 2018 based on a study in Australia (Hyland et al. 2018). As yet, we are aware of no state policy changes that would loosen restrictions on tele-abortion, despite the COVID-19 related risk of -patient visits, reduced access to contraception, difficulties obtaining usual contraception, increased sex during sheltering in place, and financial worries.

\section{Call for Action}

As $\mathrm{MCH}$ professionals must join ranks with our medical, feminist, and reproductive justice colleagues to oppose abortion bans and all efforts to exploit the COVID-19 (or other) crisis to slash women's access to legal, full sexual and reproductive health care during this epidemic and always.

Examples of critical advocacy needed to shore up SRH always and when disasters present major obstacles include support of: (1) the Women's Health Protection Act (WHPA) signed by 171 Congress persons as of May 2019, which would protect abortion access from the wave of increasingly punitive state-level laws, like Alabama's near-total ban, that prevent people from making personal decisions about their family lives; (2) allowances by Medicaid and other insurance companies to cover telemedicine as a tool for supplying medication abortion at all times; and, (3) ensuring the viability of medication supply chain protections during crises that include contraceptive drugs and devices, medication abortion, and other SRH-related drugs (Ahmed et al. 2020).

LESSON \#5: COVID-19 has exposed and deepened the fault lines in the U.S. maternity care system. Hospital birth is over-medicalized and plagued by discrimination; the entire healthcare workforce lacks racial/ethnic diversity; collaborative team approaches are underutilized; and, there are gaping holes in how women are cared for after the immediate postpartum period.

All of these problems compound the toll that systemic racism and sexism takes on women and in particular of color, resulting in high rates of maternal mortality, morbidity, and trauma associated with pregnancy among Black women.

\section{The Evidence}

Pregnancy (per se) does not appear to be a risk factor for COVID-19 infection or sequelae or transmission to infants (Weigel 2020) but pregnant women appear to display different symptomology than non-pregnant women, and may have increased risk for adverse pregnancy outcomes, 
including preterm birth and NICU admission (Allotey et al. 2020; Panagiotakopoulos et al. 2020; Delahoy et al. 2020). Being pregnant during and in the aftermath of a major crisis increases stress and elevates the risk for preterm birth, other adverse outcomes (Kreiger et al. 2018; Eskenazi et al. 2007) and pregnancy-associated mortality (Cardwell 2013). CDC's COVID-NET surveillance of hospitalized individuals from 14 states points further to disproportionate impact on BIPOC: among 577 hospitalized pregnant women with information on race and ethnicity, $42.5 \%$ were Hispanic or Latinx and $26.5 \%$ were non-Hispanic Black (Delahoy et al. 2020).

Providers have scrambled to turn emerging and continuously updated clinical guidelines into practice (Centers for Disease Control and Prevention 2020; American College of Nurse-Midwives 2020; Society for Maternal-Fetal Medicine 2020; Association of Women's Health, Obstetric and Neonatal Nurses 2020; Academy of Breastfeeding Medicine 2020). COVID-19 radically changes the birth experience for all pregnant people and their supporters. Soon after social isolation policies were rolled out, there were worrisome reports of mothers delivering alone due to restrictions on who could be present at birth (Caron and Van Syckle 2020; Van Syckle and Caron 2020). CDC changed its original more narrow guidance about who could be present during births on April 4th, allowing doulas or other non-medical persons to attend (Centers for Disease Control and Prevention 2020), but individual hospitals have been forced to limit visitors based on the availability of PPE for providers and patients.

Robust evidence that doula care is beneficial for women and for maternity care quality and cost savings suggests the potential for even greater value during a pandemic, especially for those most vulnerable to social stressors. (Kozhimannil et al. 2013, 2016; Society for Maternal-Fetal Medicine 2020; Caughey et al. 2014; National Health Law Project 2020).

Given the increased demand for midwifery care and outof-hospital birthing during COVID-19, the American College of Nurse-Midwives has called for temporary lifts on the restrictive state licensure requirements that limit access to full-scope certified nurse midwifery-led care in 24 states where certified nurse midwives are prevented from practicing to the top of their scope. "We must respond to the strain on our nation's health care workforce by allowing all health care providers to practice to the full scope of their training." (ACNM Board Treasurer Cara Krulewitch Attends White House Briefing on COVID-19 2020; American College of Nurse-Midwives 2020). Likewise, Certified Professional Midwives (CPMs) report being stretched to accommodate the growing desire for home birthing. The call for home birth is especially strong among Black women whose trust in obstetric care was broken 200 years ago and remains fragile, and in the rural South, where midwifery is tightly regulated (Morrison and Fee 2010).

\section{Call for Action}

Leverage the COVID-19 crisis to strengthen the momentum for transforming maternity care to make childbirth and motherhood safer and more holistic for everyone (Avery et al. 2018), but especially for BIPOC (Muse 2018).

Identify the mental health consequences of COVID-19 for pregnant people and provide supports. Study the various impacts of the pandemic, including sheltering in place, isolation from support systems and other as yet identified pandemic related stressors on pregnant women and their infants.

Promote, prioritize and value the role of doulas as a response to the pandemic. Work with institutions to offer a doula option to all their patients, and develop protocols for inclusion of doulas in the medical team. Join ongoing efforts to advocate for and fast-track state and federal policies regarding doula certification, licensure and reimbursement.

Support full scope of practice for CNMs and financial support for training of Black CNMs and CPMs especially in the south, where virus-related mortality and attrition have reduced the number of maternal health care workers. More Black midwives, as well as loosening of state restrictions, must be part of the solution (Simpson 2020).

LESSON \#6: The impacts of the pandemic add impetus to much-needed reforms in Medicaid policies that, if enacted due to the crisis, can have a lasting positive effect on maternal health.

\section{The Evidence}

Existing Medicaid policies are ill-suited to handle the sudden new challenges of a global and local pandemic. Because Medicaid is the largest payer of health care for pregnant and postpartum people in the U.S., covering $43 \%$ of births (Martin et al. 2018), Medicaid policy changes to respond to the crisis can have an enormous impact, especially if they build on the movements to assure reproductive justice and safe motherhood that were in the pipeline before the crisis.

Telehealth has been the most rapidly integrated and promising COVID-19-related Medicaid policy change for maternal health, yet reimbursement varies greatly and is unclear (Center for Connected Health Policy 2020). Before COVID-19, only 19 state Medicaid programs allowed reimbursement for telemedicine services delivered in the home, which limits the approach for prenatal care (Weigel et al. 2020). New guidance from Medicaid for reimbursement of telehealth services during the COVID-19 pandemic (Centers for Medicare and Medicaid 2020; Carrion 2020) has potential to help alleviate racial/ethnic and geographic inequities 
in maternal health (American College of Obstetricians and Gynecologists 2020). Telehealth for mothers can include prenatal monitoring, specialist consultations, and postpartum care. Obstacles include limited internet access in less resourced households and in rural areas, and inconsistent reimbursement requirements in different state programs (Weigel et al. 2020).

Key maternal morbidities, such as gestational diabetes, preeclampsia and hypertensive disorders are linked to future risk of chronic illness (type 2 diabetes and cardiovascular disease) (Kramer et al. 2019; Ying et al. 2018; Seely et al. 2020) - all disproportionately experienced by women of color (Garcia and Sharif 2015). These conditions require careful monitoring, testing, and postpartum follow-up, yet all were unevenly available pre-COVID-19 (McCloskey et al. 2019), in part due to loss of insurance coverage for those ineligible for continued Medicaid coverage after 60 days postpartum. One-third of pregnancy-associated deaths occur between one week and one year after birth, and most are preventable (Petersen et al. 2019). Medicaid expansions increase access, especially for women who experienced significant maternal morbidity at delivery (Gordon et al. 2020). COVID-19, with its heightened dangers for women of color, 'essential' low wage workers, mothers without secure work, food, or housing, and those with chronic illness and disabilities, makes crystal clear the importance of caring for women long after babies are born. Extending Medicaid coverage beyond 12 weeks to the full postpartum year gives women time to obtain the services they need despite the challenges of seeking care during a pandemic. The need to pass such legislation is urgent.

\section{Call for Action}

Strengthen advocacy for policy changes that COVID-19 brings to the fore. If sustained, these can advance the birth justice agenda and jumpstart the much-needed transformation of U.S. maternity care. Women of color-led organizations, including the National Birth Equity Collaborative (www.birthequity.org) and Black Mamas Matter (www.black mamasmatter.org), are leading the charge.

Key policy changes include the two we highlight above (maintaining and expanding telehealth reimbursement and extension of Medicaid coverage to one year postpartum), and four others proposed by Eckert and Yinger (2020) to assure access, quality, and continuity of care for pregnant and postpartum women during COVID-19: (1) implement presumptive eligibility for pregnant women (especially as the crisis unfolds); (2) increase income limits for pregnancyrelated Medicaid (in 15 states criteria are at 185\% FPL); (3) expand Medicaid under the Affordable Care Act (14 states and a potential 2.2 million eligible women uncovered at the level afforded by the expansion.); (4) increase access to Medicaid family planning programs (only half of states operate a Medicaid family planning program, usually for women at $200 \%$ poverty).

Prioritize the national agenda co-created by a network of patients, providers, researchers, policy-makers and health system leaders to address the fragmentation and racism in women's health care-Bridging the Chasm between Pregnancy and Health over the Life Course, funded by PCORI, NIDDK, and the Office of Research on Women's Health (BtC Collaborative et al. 2020). The agenda provides a roadmap for expanding postpartum and ongoing attention to pregnant and parenting people. COVID-19 renders much of the agenda urgent.

LESSON \#7: Social and health policy changes, heretofore deemed infeasible, ARE possible under the dire threat of mounting deaths, new shutdowns, unemployment and evictions, and the threat of economic collapse.

\section{The Evidence}

Social policies known to raise the odds for healthy mothers and families include SNAP, WIC, the earned income tax credit (Carlson and Neuberger 2017; Schanzenbach and Thorn 2019; Currie 2016), and fair wages, job protections and income supports to improve health (Khullar and Chokshi 2018). For mothers who are key breadwinners, fair wages, paid sick days, and paid medical and family leave can make or break her ability to thrive and raise healthy children.

U.S. policy-makers are able to churn out social policy reforms at lightning speed that have been previously deemed impossible, unwise, or politically infeasible. Several fasttracked and temporary policies that directly address the demands of the pandemic, are promising for bolstering maternal health in the long term; namely paid sick and family leave and family income supplements. The Families First Coronavirus Response Act (April 1, 2020) requires employers to pay for up to $80 \mathrm{~h}$ of sick leave and/or 12 weeks of paid emergency family medical leave (first 10 days unpaid). The CARES Act provides supplemental income (family checks of up to $\$ 3000$ per family) for families with incomes up to $\$ 150,000$ annual income regardless of employment status. On one hand, even conservative commentators have called out the need to fortify radical changes to create a better future, seeing public services as investments rather than liabilities..." (Financial Times Editorial Board 2020). In addition, during this time, various legislators and policy advocates are proposing universal or targeted approaches to provide direct income or savings accounts to families with children, ranging from Corey Booker's and NJ Governor Murphy's Baby Bond proposals to San Francisco's "Abundant Birth Project". The Project is the first pregnancy income supplement program in the United States; it focuses 
on low-income Black and Pacific Islander pregnant women in San Francisco (Expecting Justice 2020). On the other hand, the history of U.S. public policy tells us that pivoting from personal responsibility and victim blaming to public responsibility and social support is a tough row to hoe.

\section{Call for Action}

Align $\mathrm{MCH}$ policy and programs with cross sectoral efforts to achieve the health and well-being of female workers with low wages and families with insufficient material resources and assets: fair pay, paid leave and sick days, paid family leave, baby bonds, and supplemental income.

COVID-19 opens the door to a stronger marriage between maternal health care and economic and racial justice. Colleagues at the National Partnership for Women and Families set a strong example (National Partnership for Women and families 2020).

LESSON \#8: Finally, an overarching yet under-emphasized lesson that COVID-19 brings to the fore: we are all inextricably connected.

\section{Evidence}

At the very least, COVID-19 teaches everyone, even the most privileged, powerful, and conservative among us, that even the person one may think is less worthy is the same person planting, picking, preparing, serving and delivering food, caring for children and parents, and saving lives. COVID-19 does not respect privileges of race or class or gender; we all breathe the same air, even though the risk of contracting the disease and suffering consequences is not equally distributed. As philosopher Yuval Noah Harari, author of 21 Lessons for the Twenty-First Century, reminds us, "The world is undergoing social experiments on a massive scale" (Harari 2020). As public health professionals and as local and global citizens, we have many choices in front of us, choices that have always been there but are now in sharp relief. Economist Charles Eisenstein puts it this way, "COVID-19 is like a rehab intervention that breaks the addictive hold of normality. To interrupt a habit is to make it visible; it is to turn it from a compulsion to a choice" (Eisenstein 2020).

\section{Call for Action}

Use our voices to sustain the nation's attention on the most basic yet radical lesson of COVID-19: to put food on our tables and clothes on our bodies, build our homes and highways, drive our buses, trains, and 'Uber' cars, teach our children, care for our elderly, and when we are sick, care for us, we need us all to be healthy. And for all of us to be healthy we need a reliable social safety net that will benefit all.

\section{The Path Forward}

How do we take the lessons of the pandemic and translate them into a bolder, broader $\mathrm{MCH}$ agenda that reflects that the strength of the community depends of the resilience of the most vulnerable among us? COVID-19 has opened windows of opportunity for rapid innovation and improved access, even as it is wreaking havoc, most especially for women and families in low-income and BIPOC communities. It is inevitable and distressing that a global pandemic is diverting attention and resources from other priorities of epidemic proportion, including Black mothers' risk for death and illness in pregnancy and childbirth and a relentless opioid epidemic. Widespread public acknowledgement of the impact of social and economic inequities on the health of marginalized populations can provoke meaningful social change and renew our commitment to the "M" in $\mathrm{MCH}$ with a wider lens and more ambitious and sustainable policy goals.

Acknowledgements We wish to acknowledge the careful review and valuable assistance with references and resources provided by Dr. Judy Margo.

\section{Compliance with Ethical Standards}

Conflict of interest The authors report no conflict of interests.

\section{References}

Academy of Breastfeeding Medicine. (2020, March 10). ABM statement on Coronavirus 2019 (COVID-19). Retrieved October 10, 2020, from https://www.bfmed.org/abm-statement-coronavirus.

Ahmed, Z., Dawson, R., Donovan, M., Keller, L., \& Sonfield, A. (2020, April 8). Nine things Congress must do to safeguard sexual and reproductive health in the age of COVID-19. Retrieved October 10, 2020, from https://www.guttmacher.org/article/2020/04/ninethings-congress-must-do-safeguard-sexual-and-reproductive-healt h-age-covid-19.

Allotey, J., Stallings, E., Bonet, M., Yap, M., Chatterjee, S., Kew, T., et al. (2020). Clinical manifestations, riskfactors, and maternal and perinatal outcomes of coronavirus disease 2019 in pregnancy: Living systematic review and meta-analysis. $B M J$. https://doi. org/10.1136/bmj.m3320.

American College of Nurse Midwives. (2020, March 20). ACNM Board Treasurer Cara Krulewitch attends white house briefing on COVID-19. Retrieved October 10, 2020, from https://www. midwife.org/acnm-board-treasurer-cara-krulewitch-attends-white -house-briefing-on-covid-19.

American College of Nurse-Midwives. (2020, April). Responding to COVID-19. Retrieved October 10, 2020, from https://www.midwi fe.org/responding-to-covid-19.

American College of Obstetricians and Gynecologists. (2020, February). Implementing telehealth in practice: ACOG Committee 
Opinion Summary, Number 798. American Journal of Obstetrics \& Gynecology, 135(2), 493-494.

Association of Maternal \& Child Health Programs. (2017). Maternal and child health workforce needs. Retrieved October 10, 2020, from https://www.amchp.org/programsandtopics/WorkforceD evelopment/survey/Documents/MCH\%20Workforce\%20Nee ds\%20Infographic\%20FINAL.pdf.

Association of Schools and Programs of Public Health. (2008). Confronting the public health workforce crisis. Washington, DC: Association of Schools and Programs of Public Health.

Association of Women's Health, Obstetric and Neonatal Nurses. (2020). Novel Coronavirus (COVID-19) updates \& information. Retrieved October 10, 2020, from https://awhonn.org/novel-coron avirus-covid-19/.

Atkins, C. (2020, August 12). Texas clinics say later abortions rose after state's temporary ban. Retrieved October 10, 2020, from https://www.nbcnews.com/news/us-news/texas-clinics-say-later -abortions-rose-after-state-s-temporary-n1236442.

Avery, M., Bell, A., Bingham, D., Corry, M., Delbanco, S., Gullo, S. L., et al. (2018). Blueprint for advancing high-value maternity care through physiologic childbearing. Washington, DC: National Partnership for Women \& Families.

Baker, C. N. (2020, September 21). Abortion regulation in the age of COVID-19. The regulatory review: A publication of the Penn Program on regulation (opinion). Retrieved October 10, 2020, from https://www.theregreview.org/2020/09/21/baker-abortionregulation-covid-19/.

Bayefsky, M., Bartz, D., \& Watson, K. (2020, April). Perspective: Abortion during the Covid-19 pandemic-Ensuring access to an essential health service. The New England Journal of Medicine, 382(19), e47. https://doi.org/10.1056/NEJMp2008006.

Bloche, M. G., Balsa, A., McGuire, T., \& Seiler, N. (2003). Clinical uncertainty and healthcare disparities. American Journal of Law \& Medicine, 29, 203-219.

Bokios, T. (2020, April 15). State health care workers share struggles, demand state support during COVID-19 crisis. Retrieved October 10, 2020, from https://www.cbs58.com/news/state-healthcare -workers-share-struggles-demand-state-support-during-covid-19crisis.

Bridging the Chasm Collaborative, McCloskey, L., \& Bernstein, J. (2020). Bridging the chasm between pregnancy and health over the life course: A national agenda for research and action. Retrieved October 10, 2020, from https://www.pcori.org/sites/ default/files/BTC-Final-Report-060120.pdf.

Burnham, L., \& Theodore, N. (2012). Home economics: The invisible and unregulated world of domestic work. New York: National Domestic Workers Alliance.

Cardwell, M. (2013). Stress: Pregnancy considerations. Obstetrical \& Gynecological Survey, 68(2), 119-129.

Carlson, S., \& Neuberger, Z. (2017, March 29). WIC Works: Addressing the nurtrition and health needs of low-income families for 40 years. Retrieved October 10, 2020, from https://www.cbpp.org/ research/food-assistance/wic-works-addressing-the-nutrition-andhealth-needs-of-low-income-families.

Caron, C., \& Van Syckle, K. (2020, March 24). Some pregnant women in New York City will have to deliver babies alone. Retrieved October 10, 2020, from https://www.nytimes.com/2020/03/24/ parenting/coronavirus-labor-birth.html.

Carrion, F. (2020, April 14). Fact sheet on telehealth and medicaid during COVID-19. Retrieved October 10, 2020, from https://healt hlaw.org/resource/fact-sheet-on-telehealth-and-medicaid-durin g-covid-19/.

Castrucci, B., \& Fraser, M. (2019). Moving from data to action: Necessary next steps to a better governmental public health workforce [editorial]. Journal of Public Health Management \& Practice, 25(2 Supp), S185-S187.
Caughey, A. B., Cahill, A. G., Guise, J. M., \& Rouse, D. J. (2014). Safe prevention of the primary cesarean delivery. Obstetric Care Consensus No. 1. American Journal of Obstetrics and Gynecology, 210(3), 693-711.

Center for Connected Health Policy. (2020, April 6). COVID-19 telehealth coverage policies. Retrieved October 10, 2020, from https:// www.cchpca.org/resources/covid-19-telehealth-coverage-policies.

Centers for Disease Control and Prevention. (2020). Breastfeeding: Coronavirus disease (COVID-19). Retrieved October 10, 2020, from https://www.cdc.gov/breastfeeding/breastfeeding-specialcircumstances/maternal-or-infant-illnesses/covid-19-and-breas tfeeding.html.

Centers for Disease Control and Prevention. (2020, April 4). Coronavirus disease 2019: Caring for pregnant women. Retrieved October 10, 2020, from https://www.cdc.gov/coronavirus/2019-ncov/hcp/ inpatient-obstetric-healthcare-guidance.html.

Centers for Medicare \& Medicaid Services. (2020, April). Coronavirus waivers \& flexibilities. Retrieved October 10, 2020, from https ://www.cms.gov/about-cms/emergency-preparedness-responseoperations/current-emergencies/coronavirus-waivers.

Courage, K. H. (2020, April 9). Why are fewer women dying from the coronavirus? Retrieved October 10, 2020, from https://www. vox.com/2020/4/9/21215063/coronavirus-covid-19-deaths-menwomen-sex-dying-why.

Crenshaw, K., Poo, A.-j., Ensler, E., Flanders, L., Jr., E. G., Roberts, D., \& Stark, A. (2020, March 25). Under the blacklight: The intersectional failures that COVID-19 lays bare (part one). Retrieved October 10, 2020, from https://aapf.org/under-the-blacklight -covid19.

Crisis Standards of Care Advisory Committee, Massachusetts Department of Public Health. (2020, April 20 (revised from April 7)). Crisis standards of care planning guidance for the COVID-19 pandemic. Retrieved October 10, 2020, from https://www.mass.gov/ doc/statewide-advisory-committee-recommendations-for-stand ards-of-care/download.

Currie, J. (2016, April). How can we reduce child poverty and support parental employment? Academic Pediatrics, 16(3 Suppl), S13-S15.

Dawson, R. (2020, February 5). Trump administration's domestic gag rule has slashed the title $\mathrm{X}$ network's capacity by half. Retrieved October 10, 2020, from https://www.guttmacher.org/ article/2020/02/trump-administrations-domestic-gag-rule-hasslashed-title-x-networks-capacity-half.

Delahoy, M. J., Whitaker, M., O'Halloran, A., et al. (2020). Characteristics and maternal and birth outcomes of hospitalized pregnant women with laboratory-confirmed COVID-19-COVID-NET, 13 States, March 1-August 22, 2020. Morbidity and Mortality Weekly Report, 69(38), 1347-1354.

Eckert, E., \& Yinger, M. (2020, April 2). Five things state medicaid agencies should do now to improve care for pregnant and postpartum women amid the COVID-19 pandemic. Retrieved October 10, 2020, from https://www.healthaffairs.org/do/10.1377/hblog20200 330.454590/full/.

Enda, J. (2020, April 16). She traveled 645 miles for an abortion because of Texas ban, increasing coronavirus risks. Retrieved October 10, 2020, from https://www.houstonchronicle.com/opini on/outlook/article/She-traveled-645-miles-for-an-abortion-becau se-of-15203534.php.

Eisenstein, C. (2020, March). The coronation. Retrieved October 10, 2020, from https://charleseisenstein.org/essays/the-coronation/.

Eskenazi, B., Marks, A., Catalano, R., Bruckner, T., \& Toniolo, P. (2007). Low birthweight in New York City and upstate New York following the events of September 11th. Human Reproduction, 22(11), 3013-3020.

Evans, M., Lindauer, M., \& Farrell, M. E. (2020). A pandemic within a pandemic - Intimate partner violence during COVID-19. New 
England Journal of Medicine. https://doi.org/10.1056/NEJMp 2024046.

Expecting Justice. (2020). Cash during pregnancy: A promising approach for reducing inequities in San Francisco. Retrieved October 10, 2020, from https://www.expectingjustice.org/abund ant-birth-project/.

Farmer, B. (2020, April 2). The coronovirus doesn't discriminate, but U.S. health care showing familiar biases. Retrieved October 10, 2020, from https://www.npr.org/sections/health-shots /2020/04/02/825730141/the-coronavirus-doesnt-discriminatebut-u-s-health-care-showing-familiar-biases.

Fauteux, N. (2008). Charting nursing's future: strengthening public health nursing. Princeton, NJ: Robert Wood Johnson Foundation.

First, J., First, N., \& Houston, J. (2017). Intimate partner violence and disasters: A framework for empowering women experiencing violence in disaster settings. Afflia, 32(3), 390-403.

Financial Times Editorial Board. (2020, April 3). Virus lays bare the frailty of the social contract [Editorial]. Retrieved October 10, 2020, from https://www.ft.com/content/7eff769a-74dd-11ea-95fefcd274e920ca.

Garg, S., Kim, L., Whitaker, M., O’Halloran, A., Cummings, C., Holstein, R., et al. (2020, April 8). Hospitalization rates and characteristics of patients hospitalized with laboratory-confirmed coronavirus disease 2019-COVID-NET, 14 States, March 1-30, 2020. Morbidity and Mortality Weekly Report, 69(15), 458-464.

Glynn, S. J. (2019). Breadwinning mothers continue to be the U.S. Norm. Washington, DC: Center for American Progress.

Gordon, S., Sommers, B., Wilson, I., \& Trivedi, A. (2020, January). Effects of medicaid expansion on postpartum coverage and outpatient utilization. Health Affairs. https://doi.org/10.1377/hltha ff.2019.00547.

Gosangi, B., Park, H., Bay, C. P., Raja, A. S., Seltzer, S., Balcom, M. C., et al. (2020). Exacerbation of physical intimate partner violence during COVID-19 lockdown. Radiology. https://doi. org/10.1148/radiol.2020202886.

Gupta, A. H. (2020, October 3). Why did hundreds of thousands of women drop out of the workforce? Retrieved October 10, 2020, from https://www.nytimes.com/2020/10/03/us/jobs-women-dropp ing-out-workforce-wage-gap-gender.html.

Guttmacher Institute. (2020, April 1). Medication abortion. Retrieved October 10, 2020, from https://www.guttmacher.org/state-policy/ explore/medication-abortion.

Harari, Y. N. (2020, April 5). A historian looks ahead at a transformed post-pandemic world. Retrieved October 10, 2020, from https:// www.npr.org/2020/04/05/827582502/a-historian-looks-ahead-ata-transformed-post-pandemic-world

Hedgpeth, D., Fears, D., \& Scruggs, G. (2020, April 4). Indian country, where residents suffer disproportionately from disease, is bracing for coronavirus. Retrieved October 10, 2020, from https:// www.washingtonpost.com/climate-environment/2020/04/04/nativ e-american-coronavirus/.

Holpuch, A. (2020, August 4). The "Shecession": Why the economic crisis is affecting more women than men. Retrieved October 10, 2020, from https://www.theguardian.com/business/2020/aug/04/ shecession-coronavirus-pandemic-economic-fallout-women.

Horsley, S. (2020, April 8). Women are losing more jobs in coronavirus shutdowns. Retrieved October 10, 2020, from https://www. npr.org/2020/04/08/829141182/women-are-losing-more-jobs-incoronavirus-shutdowns.

Hyland, P., Raymond, E., \& Chong, E. (2018, June). A direct-to-patient telemedicine abortion service in Australia: Retrospective analysis of the first 18 months. The Australian \& New Zealand Journal of Obstetrics \& Gynaecology, 58(3), 335-340.

Interlandi, J. (2020, April 9). The U.S. approach to public health: Neglect, panic, repeat [Opinion]. Retrieved October 10, 2020, from https://www.nytimes.com/2020/04/09/opinion/coronaviru s-public-health-system-us.html.

Jee-Lyn Garcia, J., \& Sharif, M. (2015, August). Black lives matter: A commentary on racism and public health. American Journal of Public Health, 105(8), e27-e30.

Johnson, A., \& Buford, T. (2020, April 3). Early data shows African Americans have contracted and died of coronavirus at an alarming rate. Retrieved October 10, 2020, from https://www.propublica .org/article/early-data-shows-african-americans-have-contracted -and-died-of-coronavirus-at-an-alarming-rate.

Khullar, D., \& Chokshi, D. (2018, October 4). Health, income, \& poverty: Where we are \& what could help. Retrieved October 10, 2020, from https://www.healthaffairs.org/do/10.1377/hpb2018081 7.901935/full/.

Kochhar, R. (2020). Hispanic women, immigrants, young adults, those with less education hit hardest by COVID-19 job losses. Retrieved October 10, 2020, from https://www.pewresearch.org/ fact-tank/2020/06/09/hispanic-women-immigrants-young-adult s-those-with-less-education-hit-hardest-by-covid-19-job-losses/.

Kozhimannil, K. B., Hardeman, R., Alarid-Escudero, F., Vogelsang, C., Blauer-Peterson, C., \& Howell, E. (2016, March). Modeling the cost-effectiveness of doula care associated with reductions in preterm birth and cesarean delivery. Birth, 43(1), 20-7.

Kozhimannil, K. B., Hardeman, R., Attanasio, L., Blauer-Peterson, C., \& O'Brien, M. (2013, April). Doula care, birth outcomes, and costs among medicaid beneficiaries. American Journal of Public Health, 103(4), e113-e121.

Kramer, C., Campbell, S., \& Retnakaran, R. (2019). Gestational diabetes and the risk of cardiovascular disease in women: A systematic review and meta-analysis. Diabetologia, 62, 905-914.

Kreiger, N., Huynh, M., Li, W., Waterman, P., \& Wye, G. V. (2018). Severe sociopolitical stressors and preterm births in New York City: 1 September 2015 to 31 August 2017. Journal of Epidemiology \& Community Health, 72(12), 1147-1152.

Lewis, H. (2020, March 19). The coronavirus is a disaster for feminism. Retrieved October 10, 2020, from https://www.theatlantic.com/ international/archive/2020/03/feminism-womens-rights-coron avirus-covid19/608302/.

Martin, J., Hamilton, B., \& Osterman, M. (2018). Births in the United States, 2017. NCHS Data Brief, no. 318. Hyattsville, MD: National Center for Health Statistics.

McCloskey, L., Quinn, E., Ameli, O., Heeren, T., Craig, M., Lee-Parritz, A., et al. (2019). Interrupting the pathway from gestational diabetes mellitus to type 2 diabetes: The role of primary care. Women's Health Issues, 29(6), 480-488.

Morrison, S. M., \& Fee, E. (2010). Nothing to work with but cleanliness: The training of African American traditional midwives in the South. American Journal of Public Health, 100(2), 238-239. https://doi.org/10.2105/AJPH.2009.182873.

Muse, S. (2018). Setting the Standard for Holistic Care of and for Black Women. Atlanta, GA: Black Mamas Matter Alliance.

Nash, E., Mohammed, L., Cappello, O., \& Naide, S. (2019, December). State policy trends 2019: A wave of abortion bans, but some states are fighting back. Retrieved October 10, 2020, from https://www. guttmacher.org/article/2019/12/state-policy-trends-2019-waveabortion-bans-some-states-are-fighting-back.

National Health Law Project: Doula Medicaid Project. (2020). Retrieved October 10, 2020, from https://healthlaw.org/doula medicaidproject/.

National Partnership for Women and families. Paid Leave is Critical for Public Health (2020, July 31). Retrieved December 31, 2020 from https://www.nationalpartnership.org/our-work/resources/econo mic-justice/paid-leave/paid-leave-is-critical-for-public-health.pdf.

Panagiotakopoulos, L., Myers, T. R., Gee, J., et al. (2020). SARS$\mathrm{CoV}-2$ infection among hospitalized pregnant women: Reasons for admission and pregnancy characteristics—eight U.S. health 
care centers, March 1-May 30, 2020. Morbidity and Mortality Weekly Report, 69(38);1355-1359.

Petersen, E., Davis, N., Goodman, D., Cox, S., Mayes, N., Johnston, E., et al. (2019, May 10). Vital signs: Pregnancy-related deaths, United States, 2011-2015, and strategies for prevention, 13 States, 2013-2017. Morbidity and Mortality Weekly Report, 68(18), 423-429.

Raymond, E., Chong, E., Winikoff, B., Bednarek, P., Keady, M., \& Priegue, E. (2019, September). TelAbortion: Evaluation of a direct to patient telemedicine abortion service in the United States. Contraception, 100(3), 173-177.

Rosenbaum, S. (2017, December). The Community Health Center Fund: What's at risk? The Milbank Quarterly, 95. Retrieved October 10, 2020, from https://www.milbank.org/quarterly/artic les/community-health-center-fund-whats-risk/.

Ross, L., \& Solinger, R. (2017). Reproductive justice: An introduction. Oakland, CA: University of California Press.

Schanzenbach, D. W., \& Thorn, B. (2019, March 28). Food support programs and their impacts on very young children. Retrieved October 10, 2020, from https://www.healthaffairs.org/do/10.1377/ hpb20190301.863688/full/.

Schnall, M. (2020, April 17). Putting a gender lens on COVID-19: Thought leaders weight in. Retrieved October 10, 2020, from https ://www.forbes.com/sites/marianneschnall/2020/04/17/putting-agender-lens-on-covid-19-thought-leaders-weigh-in/.

Seely, E. W., Celi, A. C., Chausmer, J., Graves, C., Kilpatrick, S., Nicklas, J. M., et al. (2020). Cardiovascular health after preeclampsia: Patient and provider perspective. Journal of Women's Health. https://doi.org/10.1089/jwh.2020.8384.

Simpson, A. (2020, April 17). Fearing coronavirus, many rural black women avoid hospitals to give birth at home. Retrieved October 10, 2020, from https://www.pewtrusts.org/en/research-and-analy sis/blogs/stateline/2020/04/17/fearing-coronavirus-many-rural -black-women-avoid-hospitals-to-give-birth-at-home.

Sobel, L., Ramaswamy, A., Frederiksen, \& Salganicoff, A. (2020, August 10). State action to limit abortion access during the COVID-19 pandemic. Retrieved October 10, 2020, from https ://www.kff.org/coronavirus-covid-19/issue-brief/state-action-tolimit-abortion-access-during-the-covid-19-pandemic/.

Society for Maternal-Fetal Medicine. (2020, April). Publications \& clinical guidance: COVID-19. Retrieved October 10, 2020, from https://www.smfm.org/covidclinical.

Solazzo, A. (2019, November). Different and not equal: The uneven association of race, poverty, and abortion laws on abortion timing. Social Problems, 66(4), 519-547.
The state of the gender pay gap 2020. (2020, March 31). Retrieved October 10, 2020, from https://www.payscale.com/data/gende r-pay-gap.

Tucker, J., \& Patrick, K. (2017). Low-wage jobs are women's jobs: The overrepresentation of women in low-wage work. Retrieved October 10, 2020, from https://nwlc.org/wp-content/uploads/2017/08/ Low-Wage-Jobs-are-Womens-Jobs.pdf.

US Department of Health and Human Services. (2013). Public health workforce study. Retrieved October 10, 2020, from https://bhw. hrsa.gov/health-workforce-analysis/research.

Van Syckle, K., \& Caron, C. (2020, March 28). Women will not be forced to be alone when they are giving birth. Retrieved October 10, 2020, from https://www.nytimes.com/2020/03/28/parenting/ nyc-coronavirus-hospitals-visitors-labor.html.

Velonis, A., \& McGown, M. (2020). When home does not offer shelter: Partner violence in the time of pandemics. Retrieved October 10, 2020, from https://publichealth.uic.edu/news-stories/whenhome-does-not-offer-shelter-partner-violence-in-the-time-ofpandemics/.

Volkow, N. D. (2020). Collision of the COVID-19 and addiction epidemics. Annals of Internal Medicine, 173, 61-62. https://doi. org/10.7326/M20-1212.

Weigel, G. (2020, March 17). Novel Coronavirus "COVID-19": Special considerations for pregnant women. Retrieved October 10, 2020, from https://www.kff.org/womens-health-policy/issue-brief /novel-coronavirus-covid-19-special-considerations-for-pregnantwomen/.

Weigel, G., Frederiksen, B., \& Ranji, U. (2020, February 26). Telemedicine and pregnancy care. Retrieved October 10, 2020, from https://www.kff.org/womens-health-policy/issue-brief/telemedici ne-and-pregnancy-care/.

Wells, E., \& Coeytaux, F. (2016, November 8). Mail-Order abortion: The future is now. Retrieved October 10, 2020, from https://rewir e.news/article/2016/11/08/mail-order-abortion-future-now/.

Ying, W., Catov, J., \& Ouyang, P. (2018). Hypertensive disorders of pregnancy and future maternal cardiovascular risk. Journal of the American Heart Association, 7(17), e009382.

Publisher's Note Springer Nature remains neutral with regard to jurisdictional claims in published maps and institutional affiliations. 